Research Article

\title{
A prospective study on prevalence of adverse drug reactions due to antibiotics usage in otolaryngology department of a tertiary care hospital in North India
}

\author{
Farhan Ahmad Khan ${ }^{1}$, Sheikh Nizamuddin ${ }^{2}$, Najmul Huda ${ }^{3}$, Hitesh Mishra ${ }^{1}$
}

\begin{abstract}
${ }^{1}$ Department of Pharmacology, ${ }^{2}$ Department of ENT,

${ }^{3}$ Department of Orthopaedics, Teerthanker Mahaveer Medical College and Research Centre, TMU, Moradabad-244001, India
\end{abstract}

Received: 23 June 2013

Accepted: 21 July 2013

*Correspondence to:

Dr. Farhan Ahmad Khan, Email: dr.farhan.k@gmail.com

(C) 2013 Khan FA et al. This is an open-access article distributed under the terms of the Creative Commons Attribution Non-Commercial License, which permits unrestricted non-commercial use, distribution, and reproduction in any medium, provided the original work is properly cited.

\begin{abstract}
Background: Polypharmacy, advancing age and longer duration of hospital stay are the factors responsible for adverse drug reactions (ADRs). This study has attempted to analyze the pattern of antimicrobial prescription in OPD \& IPD of the Otolaryngology department and to detect, document, assess and report the suspected ADRs due to antibiotic use and preparation of guidelines to minimize the incidence of ADRs.

Methods: A prospective study conducted at the TMMC\&RC on patients aged $>40$ years, who visited the Otolaryngology department over a period of 5 months. Suspected ADRs were assessed for causality and severity using Naranjo's probability scale and modified Hartwig's criteria, respectively.

Results: Out of 1200, 925 prescriptions were analyzed. Most patients were from $41-60$ age $(59.45 \%)$ followed by $61-80$ age $(37.29 \%)$ and least from $>80$ $\mathrm{yr}(3.24 \%)$. But the incidence of ADRs were found to be higher in patients of $>80$ yr age group $n=8(26.66 \%)$. The most commonly prescribed antibacterials were $\beta$-Lactams (64.61\%). Out of 925 prescriptions studied, only 94 were found to have 154 ADRs. The most commonly identified ADRs were Gastrointestinal $47.40 \%$, followed by Neurotoxicity $24.67 \%$, cutaneous reactions $20.12 \%$, Hepatic $4.54 \%$ and Kidney 3.24\%. $74.67 \%$ of the ADRs were probable and $20.77 \%$ were possible type and only $4.54 \%$ were definite. $74.67 \%$ ADRs were found to be type A, and $25.32 \%$ type B.

Conclusions: Our study showed that prevalence of ADRs was highest in elder age group and diarrhea was the most common ADR found. Therefore elderly patients should be given special attention when prescribing medications to avoid clinically significant harmful consequences. Minimizing unnecessary antibiotic use by even a small percentage could significantly reduce the immediate and direct risks of drug-related adverse events in individual patients.
\end{abstract}

Keywords: Antibacterial agents, Drug utilization, Adverse Drug reactions

\section{INTRODUCTION}

Polypharmacy (prescribing more than five drugs concurrently) is more common in elderly patients because of existences of one or more diseases. But multiple medication increases the incidence of Adverse drug reactions (ADRs). ADRs as per the WHO definitions is "a response to a drug that is noxious and unintended and occurs at doses normally used in man for the prophylaxis, diagnosis or therapy of disease, or for modification of physiological function". Moreover, other definition specifically excludes minor unwanted reactions (e.g., a slight dryness of the mouth): "A harmful or significantly unpleasant effect caused by a drug at doses intended for therapeutic effect (or prophylaxis or diagnosis) which warrants reduction of dose or withdrawal of the drug and/or foretells hazard from future administration." However, these definitions (and others reviewed elsewhere) exclude error as a source of adverse effects. ${ }^{2,3}$ ADRs have been found to enhance morbidity and mortality during hospitalizations. ${ }^{4}$

ADRs have becomes an important challenge in today's modern medicine, ranked between the fourth and sixth leading causes of death in the USA. Very few studies on ADRs as the cause of hospital admissions were carried out in India. This compelled us to analyze the prevalence of ADRs as well as associated risk factors in elderly population of North India. Infections are one of the most important causes of patients visit in the hospital and Otolaryngology 
department is one of those where consumption of antibiotics are higher. Therefore we have chosen Antibiotics for studying the incidence of ADRs associated with them. The reason being is the enormous use of antimicrobial agents in the hospitals. There was also problem of irrational prescribing of antibiotics leading to antimicrobial. This will also affect the patients such as increase in the medical costs; patients do not get professionally appropriate prevention services or treatments.

\section{METHODS}

It was a prospective study conducted on all the patients aged $\geq 40$ yr who visited the ENT department during the 5-month study period and were prescribed medication(s) were included in the study. Out of 1200 patients enrolled, only 925 prescriptions were available for analysis and data of 275 patients with incomplete information were excluded.

All the demographic details and prescribed medications were collected using structured format. It contains patient age, gender, diagnosis, past medications, currently prescribed drugs, their brand names, daily doses, and treatment durations.

Prior to study adverse drug reaction forms were made available in OPD and clinical wards of ENT. ADR boxes have been installed in OPD as well as IPD. ADR reports were accepted from all the healthcare professionals of ENT specialty, interns, nurses and also from patients. Patients were encouraged to report any type of unwanted reaction they suffer during the treatment in the hospital. The causality relationship between suspected drug and reaction was established by using WHO and Naranjo's causality assessment scales and categorized into definite (score >9), probable (score 5-8), possible (score 1-4) or doubtful (score 0). ${ }^{5}$ Severity of the identified ADRs was assessed using Modified Hartwig's criteria. ${ }^{6}$

Only those ADRs which are associated with antibiotics were accounted in the study. The adverse drug reactions based on the causes were classified on the basis of Edward \& Aronson classification system. According to this, there are six types of ADRs namely Type A (augmented pharmacologic effects), Type B (bizarre effects), Type C (chronic effects), Type D (delayed effects), Type E (end-of-treatment effects) and Type F (failure of therapy). ${ }^{7}$

The protocol of the study was approved by the Research and Bioethical Committee of the hospital. A written informed consent was taken from all the patients enrolled prior to the study.

\section{RESULTS}

925 prescriptions were collected from OPD and IPD of ENT department. Out of 925 patients, 502 were males and 423 female. Majority of the patients were from 41-60 age group $\mathrm{n}=550(59.45 \%)$ followed by $61-80$ age group, $\mathrm{n}=345(37.29 \%)$ and least from $>80$ yr group, $\mathrm{n}=30$ (3.24\%) [Table 1]. But the incidence of ADRs were found to be higher in patients of $>80 \mathrm{yr}$ age group $\mathrm{n}=8(26.66 \%)$ followed by 61-80 year age group, $n=46(13.33 \%)$ and lowest in 41-60 year group, $\mathrm{n}=40(7.27 \%)$ [Table 1]. During the study, it was observed that 410 patients visited for treating ear disorders, 175 for nasal disorders, and 245 for throat infections and 95 for combined ENT infections [Table 2]. Most of the ADRs were seen in patients treating for throat infections $(n=46)$ and least in patients suffering from nasal disorders $(n=12)$ [Table 1].

Table 1: Risk factors associated with adverse drug reactions (ADRs).

\begin{tabular}{|c|c|c|}
\hline Variable & $\begin{array}{l}\text { Total No. of } \\
\text { Patients }\end{array}$ & $\begin{array}{l}\text { Total No. of } \\
\text { patients with } \\
\text { ADR }\end{array}$ \\
\hline $\begin{array}{l}\text { Age (year) } \\
41-60 \\
61-80 \\
>80 \\
\text { Total }\end{array}$ & $\begin{array}{l}550(59.45 \%) \\
345(37.29 \%) \\
30(3.24 \%) \\
925\end{array}$ & $\begin{array}{l}40(7.27 \%) \\
46(13.33 \%) \\
8(26.66 \%) \\
94(\mathbf{1 0 . 1 6 \% )}\end{array}$ \\
\hline $\begin{array}{ll}\text { Diseases } \\
\text { - } & \text { Ear disorders } \\
\text { - } & \text { Nasal disorders } \\
\text { - } & \text { Throat disorders } \\
& \text { Combined ENT } \\
& \text { Infections }\end{array}$ & $\begin{array}{l}410 \\
175 \\
245 \\
95\end{array}$ & $\begin{array}{l}22 \\
12 \\
46 \\
14\end{array}$ \\
\hline $\begin{array}{l}\text { No. of medications per } \\
\text { prescription } \\
\qquad \quad<5 \\
-\quad>5\end{array}$ & $\begin{array}{l}620 \\
305\end{array}$ & $\begin{array}{l}35(5.64 \%) \\
59(19.34 \%)\end{array}$ \\
\hline $\begin{array}{l}\text { Duration of hospital } \\
\text { stay (days) } \\
-\quad<7 \\
-\quad>7 \\
\end{array}$ & $\begin{array}{l}410 \\
515\end{array}$ & $\begin{array}{l}28(6.82 \%) \\
66(12.81 \%)\end{array}$ \\
\hline $\begin{array}{l}\text { ADR Reporting }(\mathbf{n}=\mathbf{3 5 0}) \\
\text { - } \quad \text { Physicians, interns } \\
\text { - } \quad \text { Nurses } \\
\quad \text { atients }\end{array}$ & $\begin{array}{l}50 \\
80 \\
220\end{array}$ & $\begin{array}{l}22 \\
25 \\
47\end{array}$ \\
\hline
\end{tabular}

The most commonly prescribed antibacterials were $\beta$ Lactams $(64.61 \%)$ followed by Quinolones $(12.57 \%)$, Macrolide (11.89\%), Aminoglycosides (6.59\%) and Nitroimidazoles $(4.31 \%)$ [Table 2].

Out of 925 prescriptions studied, only 94 were found have one or more ADRs. The total number of ADRs was 154 in 94 prescriptions. The most commonly identified ADRs were Gastrointestinal $n=73,47.40 \%$ (Diarrhoea, vomiting and metallic taste), followed by Neurotoxicity $\mathrm{n}=38,24.67 \%$ (vertigo, decrease in hearing), Cutaneous reactions $\mathrm{n}=31,20.12 \%$ (rashes, urticaria, Stevens Johnson Syndrome), Hepatic $\mathrm{n}=7,4.54 \%$ (raised liver enzymes) and Kidney $\mathrm{n}=5,3.24 \%$ (Interstitial nephritis, Acute tubular necrosis) [Table 3], Fig. 1. The most common offending class of drug responsible for ADRs were $\beta$-Lactams $(n=55)$ followed by Aminoglycoside $(\mathrm{n}=46)$, Macrolide $(\mathrm{n}=24)$, Nitroimidazoles $(\mathrm{n}=16)$ and Quinolones ( $\mathrm{n}=13)$ [Table 3]. 
Table 2: Antimicrobials prescribed $(n=1622)$.

\begin{tabular}{|c|c|c|c|}
\hline Class & Antibacterial agents & $\begin{array}{l}\text { No. of agents } \\
\text { prescribed }\end{array}$ & Consumption \% \\
\hline \multirow{10}{*}{$\beta$-Lactams } & Amoxicillin & 65 & 4.00 \\
\hline & Ampicillin+ Cloxacillin & 125 & 7.70 \\
\hline & Amoxicillin + Clavulanic acid & 135 & 8.32 \\
\hline & Cefpodoxime & 80 & 4.93 \\
\hline & Cefixime & 280 & 17.26 \\
\hline & Cefixime+ Clavulanic acid & 103 & 6.35 \\
\hline & Cefixime+ Ofloxacin & 100 & 6.16 \\
\hline & Ceftriaxone & 125 & 7.70 \\
\hline & Cefuroxime & 35 & 2.15 \\
\hline & Total & 1048 & 64.61 \\
\hline \multirow{6}{*}{ Quinolones } & Ciprofloxacin & 73 & 4.50 \\
\hline & Ofloxacin & 38 & 2.34 \\
\hline & Levofloxacin & 48 & 2.95 \\
\hline & Gatifloxacin & 35 & 2.15 \\
\hline & Gemifloxacin & 30 & 1.84 \\
\hline & Total & 204 & 12.57 \\
\hline \multirow{3}{*}{ Aminoglycosides } & Amikacin & 77 & 4.74 \\
\hline & Gentamicin & 30 & 1.84 \\
\hline & Total & 107 & 6.59 \\
\hline \multirow{3}{*}{ Macrolide } & Azithromycin & 148 & 9.12 \\
\hline & Clarithromycin & 75 & 4.62 \\
\hline & Total & 193 & 11.89 \\
\hline \multirow{4}{*}{ Nitroimidazoles } & Ornidazole & 50 & 3.08 \\
\hline & Metronidazole & 20 & 1.23 \\
\hline & Total & 70 & 4.31 \\
\hline & Grand Total & 1622 & 100 \\
\hline
\end{tabular}

Majority of the patients received less than 5 medications $(n=620)$ and remaining were prescribed more than five medications $(n=305)$. Prevalence of ADRs were higher in patients receiving more than five drugs (19.34\%) in comparison to less than five drugs (5.64\%) [Table 1]. Patients hospitalized for more than a week were suffered from more ADRs (12.81\%) than those with a hospital stay of less than 7 days $(6.82 \%)$ [Table 1]. Out of 350 ADR related queries received from different sources, only 154 were established as ADRs. Most of the queries were asked by the patients $(n=220)$, followed by nurses $(n=80)$ and least by doctors and interns $(n=50)$. But the success rate of queries (established as ADRs) were higher in cases of doctors and interns $(44.0 \%)$ and least in cases of patients $(21.36 \%)$ [Table 1$]$. 
Table 3: Incidence of ADRs in drug classes $(n=154)$ in 94 prescriptions.

\begin{tabular}{|c|c|c|c|}
\hline \multirow[b]{2}{*}{$\begin{array}{l}\text { Identified } \\
\text { drugs/class }\end{array}$} & \multicolumn{3}{|c|}{ Identified ADR } \\
\hline & Allergic reactions (31) & $\begin{array}{l}\text { GI }(\text { Diarrhea }=55), \\
(\text { Vomiting }=13),(\text { Metallic } \\
\text { taste }=5), \\
\text { Hepatotoxicity }=7, \\
\text { Neurotoxicity }=1\end{array}$ & $\begin{array}{l}\text { Neurotoxicity (vertigo, } \\
\text { decrease in hearing)=(37) } \\
\& \text { Nephrotoxicity }(5)\end{array}$ \\
\hline$\beta$-Lactams (55) & $\begin{array}{l}\text { Rashes }(\mathbf{1 4})=\text { Amoxicillin, } \\
\text { Amoxicillin+Clavulanic } \\
\text { acid, } \\
\text { Urticaria }(\mathbf{2})=\text { Cefixime+ } \\
\text { Clavulanic acid } \\
\text { Stevens Johnson } \\
\text { Syndrome }(\mathbf{3})=\text { Cefixime+ } \\
\text { Clavulanic acid }\end{array}$ & 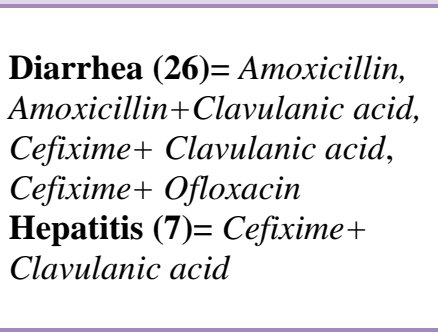 & $\begin{array}{l}\text { Interstitial nephritis }(\mathbf{3})= \\
\text { Amoxicillin }\end{array}$ \\
\hline Quinolones (13) & $\begin{array}{l}\text { Rashes }(\mathbf{3})=\text { Gatifloxacin, } \\
\text { Stevens Johnson } \\
\text { Syndrome (3)= Ofloxacin }\end{array}$ & $\begin{array}{l}\text { Diarrhea }(\mathbf{3})=\text { Ciprofloxacin, } \\
\text { Vomiting } \mathbf{( 4 )}=\text { Gatifloxacin }\end{array}$ & \\
\hline $\begin{array}{l}\text { Aminoglycoside } \\
\text { (46) }\end{array}$ & Rashes $(2)=$ Gentamicin & Vomiting (5) = Amikacin & $\begin{array}{l}\text { Decrease in hearing (15), } \\
\text { Vertigo }(\mathbf{2 2})=\text { Amikacin, } \\
\text { Gentamicin, } \\
\text { Acute tubular necrosis } \\
(\mathbf{2})=\text { Gentamicin }\end{array}$ \\
\hline Macrolide (24) & Rashes (1) )= Azithromycin & $\begin{array}{l}\text { Diarrhea }(\mathbf{2 0})=\text { Azithromycin, } \\
\text { Decrease in hearing }(\mathbf{1})= \\
\text { Azithromycin, } \\
\text { Vomiting }(\mathbf{2})= \\
\text { Clarithromycin }\end{array}$ & \\
\hline $\begin{array}{l}\text { Nitroimidazoles } \\
\text { (16) }\end{array}$ & Rashes (3)= Ornidazole & $\begin{array}{l}\text { Diarrhea }(\mathbf{6})=\text { Ornidazole, } \\
\text { Metallic taste }(\mathbf{5})= \\
\text { Metronidazole } \\
\text { Vomiting }(\mathbf{2})=\text { Ornidazole }\end{array}$ & \\
\hline
\end{tabular}

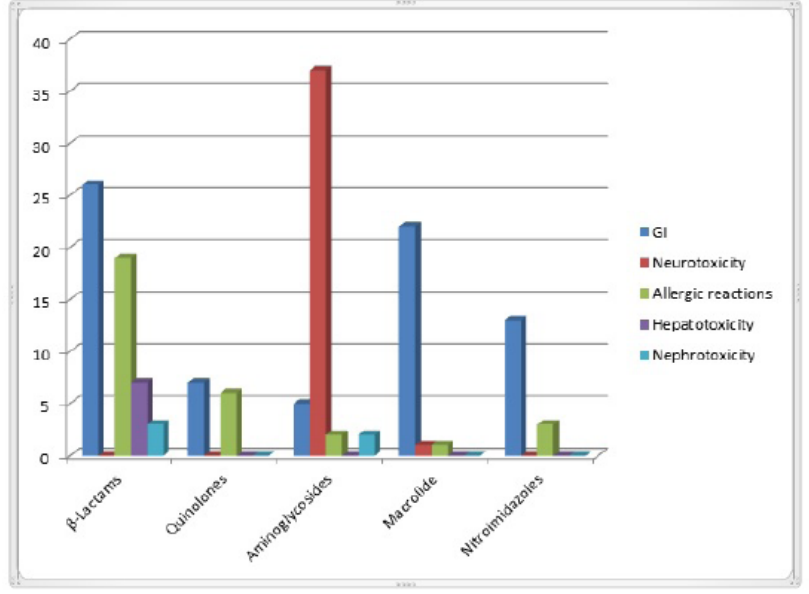

Figure 1: Incidence of ADRs in drug classes.

On the basis of WHO and Naranjo's causality assessment scales, over $74.67 \%(n=115)$ of the ADRs were probable,
$32(20.77 \%)$ ADRs were possible type and only 7 $(4.54 \%)$ were definite.

Based on modified Hartwig severity scale, most of the reactions were categorized as mild (120 of 154), 30 ADRs were moderate type and only four ADRs were 'severe' in nature. 115 (74.67\%) ADRs were found to be type A, whereas 39 (25.32\%) type B.

From the above mentioned data it can be seen patients with advance age, multiple medications and longer hospital stay were more likely to have ADRs.

\section{DISCUSSION}

In our study, prevalence of ADRs was found to be $10.16 \%$ per cent in elderly patients visiting the OPD \& IPD of Otolaryngology department during 5 month study period. These findings are consistent with similar prospective study conducted by Mandavi. et al (2012) in 
hospitalized patients which used a similar methodology as the present study showing $10 \%$ ADR prevalence in elderly population. ${ }^{8}$ Some other similar studies showed higher incidence of ADRs as Schneider et al (1992) reported 21 percent, Demissew BH et al (2013) reported $16.2 \%$ when compared to our study. ${ }^{4,9-12}$ However, the figure in this study is higher than $3.7 \%$ incidences which were observed in a prospective study by Ramesh et al. (2003). ${ }^{13}$ Similar studies conducted in other part of India showed lower prevalence rates such as prevalence of $0.15 \%$ only by Jose et al. (2006) in Karnataka. ${ }^{14}$ The difference in prevalence rate may be due to the fact that South India (Karnataka) has more literacy rate than North India. People of South India are more aware of ADRs in comparison to our populations. Also we have taken ADR queries from different sources. We have chosen antibiotics in our study as well supported by Jose J. et al (2006), Demissew BH. et al (2013) as the drug classes to cause most of the ADRs.

In our study, most commonly identified ADRs were Gastrointestinal $n=73,47.40 \%$ (Table 3, Figure 1). Our findings are consistent with Camargo AL. et al (2006) showing gastrointestinal ADRs mostly encountered ADRs. ${ }^{15}$ Second most ADRs found in our study belongs to Neurotoxicity (24.67\%) followed by Cutaneous ADRs (20.12\%). The higher percentage of neurotoxicity is mainly because of Aminoglycosides. In a study conducted by Smith CR et al (1980) showed Aminoglycosides causing ototoxicity or vestibular dysfunction in patients. ${ }^{16}$ One of our patient has suffered decrease in hearing due to Azithromycin that reversed after 2 weeks of discontinuation of the agent. This is well documented in the previous studies showing Erythromycin and azithromycin can cause bilateral hearing loss or labyrinthine dysfunction. ${ }^{17}$ Allergic reactions were third most ADRs found in our study. Our findings are well supported by Klimek L. et al (2013) showing Allergic reactions to antibiotics are among the most frequently reported adverse side effects arising from drug treatment in Otolaryngology department. ${ }^{14,18}$ The combination of Cefixime+Clavulanic acid have caused increased liver enzymes in 7 patients, our finding well supported by previous studies showing Semisynthetic penicillins are frequent causes of hepatotoxicity, especially when combined with clavulanic acid. ${ }^{19}$ Interstitial nephritis was also found in our study in patients consuming $\beta$-Lactam antibiotics (Amoxycillin). The findings of this study were in accordance with recent studies showing $\beta$-Lactam antibiotics causing Interstitial nephritis. ${ }^{20}$

According to the result of our study, type A reactions accounted for $74.67 \%$ of the ADRs while $25.32 \%$ ADRs were of type B. This was in agreement with the definition of type A reactions that are more common and predictable and type $\mathrm{B}$ reactions that are uncommon. Moreover, our results were consistent with the reports of studies carried out in Karnataka where type A ADRs were found to be $72.5 \% .^{14}$
Camargo AL. et al (2006) and Onder G. et al (2002) have shown that patients taking more medications suffer from ADRs. Likewise, the present study also revealed number of drugs as a significant risk factor for ADRs with each additional medication multiplying the risk of an ADR. ${ }^{15,21}$ Our study revealed that patients with longer hospital stay were more prone to develop ADRs. This is in accordance with other studies showing the same fact. ${ }^{9}$

\section{CONCLUSION}

The present work is the maiden prospective study carried out in our hospital and has shown elderly patients are more prone to ADRs, may be due to suffering from one or more diseases. Therefore this population requires special care when prescribing medication. The ADR prevalence rate is higher in comparison to other studies carried out in other parts of India. That was a signal for a need for intervention and increased prevention level in ADR related health problems. It is important to note that better knowledge of preventable ADRs could help to design preventive strategies to protect patients from being affected by these reactions unnecessarily. Also ADR reporting from doctors were found to be least, therefore awareness and ADR monitoring programmes should be started in the hospitals for better understanding of ADR reporting. The awareness of risk factors of ADRs would help physicians to identify elderly patients with greater risk of ADRs and, therefore, might benefit from ADRs monitoring and reporting programme. Such similar studies should be conducted periodically to assess the success rates of awareness programmes.

\section{ACKNOWLEDGEMENTS}

We would like to thank the nursing and medical staffs of the study hospital for their cooperation for the success of the study.

Funding: Nil

Conflict interest: None declared

Ethical approval: Approved by the Research and Bioethical Committee of the Hospital

\section{REFERENCES}

1. WHO. International drug monitoring: the role of national centers. Tech Rep Ser WHO 1972, no 498.

2. Laurence D, Carpenter J. A dictionary of pharmacology and allied topics, 2nd edn. Amsterdam: Elsevier, 1998: 8-9.

3. Stephens MDB. Definitions and classifications of adverse reaction terms. In: Stephens MDB, Talbot JCC, Routledge PA, eds. The detection of new adverse reactions, 4th edn. London: Macmillan Reference, 1998: 32-44.

4. Lazarou J, Pomeranz BH, Corey PN. Incidence of adverse drug reactions in hospitalized patients: a meta-analysis of prospective studies. JAMA. 1998;279(15):1200-5. 
5. Naranjo CA, Busto U, Sellers EM, Sandor P, Ruiz I, Roberts EA, et al. A method for estimating the probability of adverse drug reactions. Clin Pharmacol Ther 1981;30:239-45.

6. Chan M, Nicklason F, Vial JH. Adverse drug events as a cause of hospital admission in the elderly. Intern Med J 2001; 31:199-205.

7. Edwards IR, Aronson JK. Adverse drug reactions: definitions, diagnosis, and management. Lancet 2000; 356: 1255-9.

8. Mandavi, Sanjay D'Cruz, Atul Sachdev \& Pramil Tiwari. Adverse drug reactions \& their risk factors among Indian ambulatory elderly patients. Indian J Med Res 136, September 2012, pp 404-410.

9. Davies EC, Green CF, Mottram DR, Pirmohamed M. Adverse drug reactions in hospital in-patients: a pilot study. J Clin Pharm Ther. 2006; 31:335-41.

10. Davies EC, Green CF, Taylor S, Williamson PR, Mottram DR, Pirmohamed M. Adverse drug reactions in hospital in-patients: a prospective analysis of 3695 patient-episodes. PLoS one. 2009; 4(2):e4439.

11. Schneider JK, Mion LC, Frengley JD. Adverse drug reactions in an elderly outpatient population. Am J Hosp Pharm 1992; 49 : 90-6.

12. Demissew BH, Wubeante YA, and Tiwari P. Prevalence and Assessment of Factors Contributing to Adverse Drug Reactions in Wards of a Tertiary Care Hospital, India. Ethiop J Health Sci. 2013 March; 23(1): 39-48.

13. Ramesh M, Pandit J, Parthasarathi G. Adverse drug reactions in a South Indian hospital - their severity and cost involved. Pharmacoepidemiol Drug Saf. 2003; 12:687-92.
14. Jose J, Padma GM. Pattern of adverse drug reactions notified by spontaneous reporting in an Indian tertiary care teaching hospital. Pharmacol Res. 2006; 54:226-33.

15. Camargo AL, Cardoso Ferreira MB, Heineck I. Adverse drug reactions: a cohort study in internal medicine units at a university hospital. Eur J Clin Pharmacol. 2006;62:143-9.

16. Smith CR, Lipsky JJ, Laskin OL. Double-blind comparison of the nephrotoxicity and auditory toxicity of gentamicin and tobramycin. $\mathrm{N}$ Engl J Med 1980;302:1106-9.

17. Umstead GS, Neumann KH. Erythromycin ototoxicity and acute psychotic reaction in cancer patients with hepatic dysfunction. Arch Intern Med 1986;146:897-9.

18. Klimek L, Aderhold C, Sperl A. [Allergies to antibiotic drugs: Their importance in otorhinolaryngology]. HNO. 2013 May;61(5):40915. doi: 10.1007/s00106-012-2599-6.

19. Brown SJ, Desmond PV. Hepatotoxicity of antimicrobial agents. Semin Liver Dis 2002;22:15767.

20. Alexopoulos E. Drug-induced acute interstitial nephritis. Ren Fail 1998;20:809-19.

21. Onder G, Pedone C, Landi F, et al. Adverse drug reactions as cause of hospital admissions: results from the Italian Group of Pharmacoepidemiology in the elderly (GIFA). J Am Geriatr Soc. 2002;50:1962-8.

doi:10.5455/2319-2003.ijbcp20131007

Cite this article as: Khan FA, Nizamuddin S, Huda $\mathrm{N}$, Mishra H. A prospective study on prevalence of adverse drug reactions due to antibiotics usage in otolaryngology department of a tertiary care hospital in North India. Int J Basic Clin Pharmacol 2013;2:548-53. 